\title{
RESISTÊNCIA À CORROSÃO DE FILMES HÍBRIDOS APLICADOS SOBRE FOLHAS DE FLANDRES: SOLUÇÃO PRECURSORA ACIDIFICADA COM ÁCIDO NÍTRICO $(\mathrm{pH}=3)^{1}$
}

\author{
Sandra Raquel Kunst ${ }^{2}$ \\ Paloma Bertoli ${ }^{3}$ \\ Karine Parise ${ }^{3}$ \\ Gustavo Ludwig ${ }^{4}$ \\ Iduvirges Lourdes Muller \\ Célia de Fraga Malfatti
}

Resumo

Os pré-tratamentos baseados nos sistemas siloxano-PMMA têm mostrado resultados promissores atraindo também a atenção das indústrias nos últimos anos, pois esses revestimentos híbridos melhoram as características de proteção contra a corrosão das folhas de flandres e as propriedades de adesão dos revestimentos orgânicos sobre esse substrato, além de provocar menores impactos ambientais comparados à cromatização. $O$ objetivo do presente trabalho é revestir as folhas de flandres com um filme híbrido obtido a partir de um sol constituído pelos precursores alcoóxidos: 3-(trimetoxisililpropil)metacrilato (TMSM), poli(metacrilato de metila) PMMA e tetraetoxisilano (TEOS) variou-se em três níveis a concentração de TEOS (1, 2 e 3). Os filmes foram obtidos pelo processo de dipcoating e tratados termicamente por 3 horas numa temperatura de $160^{\circ} \mathrm{C}$. Avaliou-se a hidrofobicidade dos revestimentos através de medidas de ângulo de contato. Os filmes híbridos obtidos foram caracterizados quanto ao comportamento eletroquímico e morfológico. Os resultados mostraram que o filme híbrido siloxano-PMMA com maior concentração de TEOS apresentou maior espessura, no entanto, devido à intensa densificação do filme promovida pela adição de TEOS, houve a formação de fissuras, comprometendo desse modo a resistência à corrosão.

Palavras-chaves: Silanos; Ácido nítrico; Folha de flandres; Corrosão; TEOS.

\section{CORROSION RESISTANCE OF HYBRID FILMS APPLIED ON TIN PLATE: PRECURSOR SOLUTION ACIDIFIED WITH NITRIC ACID $(\mathrm{pH}=3)$}

\section{Abstract}

Pretreatments systems based on siloxane-PMMA have shown promising results also attracting the attention of industries in recent years because these hybrid coatings improve the characteristics of corrosion protection of tin plates and the adhesion properties of organic coatings on this subr'- $¥$ te, and cause less environmental impacts compared to chromating. The aim of this work is to coat tin plate with a hybrid film obtained from a sol consisting of -11....... ….......... n 1........thoxysilylpropyl) methacrylate (TMSM), poly (methyl meulaciyide) rivivia viur teudeuroxysilane (TEOS) was varied in three levels, the concentration of TEOS (1, 2 and 3). The films were obtained by dip-coating process, cured for 3 hours at $160^{\circ} \mathrm{C}$. The film hydrophobicity was determined by the contact angle measurements. The hybrid films were characterized as the morphological and electrochemical behavior. The results showed that the hybrid film siloxane-PMMA with a higher concentration of TEOS showed increased thickness, however, due to the intense densification of the film promoted by the addition of TEOS, there was the formation of cracks, thereby compromising the corrosion resistance.

Key words: Silanes; Nitric acid; Tinplate; Corrosion; TEOS.

1 Contribuição técnica ao $68^{\circ}$ Congresso Anual da ABM - Internacional, 30 de julho a 2 de agosto de 2013, Belo Horizonte, MG, Brasil.

2 Engenheira química. Doutoranda, Laboratório de Pesquisa em Corrosão (LAPEC), PPGEM, UFRGS. Porto Alegre, RS, Brasil.

Graduanda Eng. Metalúrgica, LAPEC, PPGEM, UFRGS. Porto Alegre, RS, Brasil.

Engenheiro mecânico. Mestrando, LAPEC, PPGEM, UFRGS. Porto Alegre, RS, Brasil.

Engenheira eletricista. Professora Doutora, LAPEC, PPGEM, UFRGS. Porto Alegre, RS, Brasil.

Engenheira metalúrgica. Professora Doutora, LAPEC, PPGEM, UFRGS. Porto Alegre, RS, Brasil. 


\section{INTRODUÇÃO}

As principais aplicações de embalagens de folha de flandres são 0 acondicionamento de produtos alimentícios e de produtos não alimentícios. ${ }^{(1)} \mathrm{Em}$ relação à qualidade da folha de flandres, merecem destaque a presença de óxidos de estanho na superfície e a camada de passivação. Entretanto, a presença de excessivas quantidades desses óxidos pode alterar a aparência, a soldabilidade da folha metálica e a capacidade de receber revestimentos orgânicos. ${ }^{(2)}$ Atualmente as embalagens utilizam os tratamentos superficiais baseadas no uso de cromatos, pois estes propiciam aos metais uma excelente resistência à corrosão. ${ }^{(3)}$

Alternativas não tóxicas de pré-tratamentos têm sido desenvolvidos nos últimos anos para substituir o processo de cromatização. Entre as possíveis alternativas, estão os pré-tratamentos estão os filmes híbridos obtidos pelo processo sol-gel. ${ }^{(4)}$

Híbridos sol-gel são materiais muito versáteis que combinam propriedades de materiais inorgânicos e orgânicos. As redes híbridas podem ser convenientemente divididos em três classes gerais. A classe I corresponde aos sistemas híbridos, onde as moléculas orgânicas, oligômeros, ou polímeros de baixo peso molecular orgânicas são simplesmente incorporados em uma matriz inorgânica. A classe II corresponde aos híbridos orgânico-inorgânicos, onde os componentes orgânicos e inorgânicos são ligados por meio de ligações químicas fortes, seja por ligações covalentes ou iónicas-covalente. Híbridos de classe III consistem basicamente em fusão classe I com os híbridos de classe II, reunindo as propriedades de adesão de uma com a rede inorgânica-orgânica fornecida pelo outro. ${ }^{(5)} \mathrm{A}$ obtenção de novos híbridos a partir do PMMA vem sendo investigada ${ }^{(6-9)}$ a fim de se obter revestimentos com espessura de alguns micrometros sem trincas. Além disso, devido a estabilidade do PMMA a radiação laser e a facilidade de polimerização dos grupos metacrilato (MMA) seja por radiação $U^{(10)}$ ou por tratamentos térmicos, o que possibilita aumentar o índice de refração.

O objetivo do presente trabalho é estudar a resistência a corrosão dos filmes híbridos e o efeito da adição do tetraetóxisilano (TEOS) no filme quando aplicados sobre as folhas de flandres.

\section{MATERIAIS E MÉTODOS}

\subsection{Preparação da Superfície}

As folhas de flandres foram lavadas com acetona e secas com ar quente. Posteriormente, foram desengraxados com detergente neutro $(\mathrm{pH}=7)$, à $70^{\circ} \mathrm{C}$ por imersão durante 10 minutos. Em seguida foram lavados com água deionizada e secos e novamente foram lavados com acetona e secos com ar quente.

\subsection{Elaboração dos filmes híbridos siloxano-PMMA}

Os filmes híbridos foram obtidos sobre o substrato de folhas de flandres a partir de um sol constituído pelos precursores silanos: 3-(trimetoxisililpropil)metacrilato (TMSPMA - $\mathrm{C}_{10} \mathrm{H}_{20} \mathrm{O}_{5} \mathrm{Si}$ ) e tetraetoxissilano (TEOS - $\mathrm{C}_{8} \mathrm{H}_{20} \mathrm{O}_{4} \mathrm{Si}$ ), com adição de metacrilato de metila (MMA). A metodologia sol-gel foi empregada na preparação dos materiais híbridos orgânico-inorgânicos. Na preparação da fase inorgânica, foi realizada a síntese dos precursores TEOS e TMSM esses foram misturados a $60^{\circ} \mathrm{C}$ por 1 hora e a hidrólise foi efetuada em meio de $\mathrm{pH}=3$, utilizando ácido nítrico como 
catalisador e etanol e água como solventes. A fase orgânica consistiu na homogeneização à temperatura ambiente do MMA, onde o iniciador térmico é o peróxido de benzoíla (BPO). Finalmente as duas soluções (orgânicas e inorgânicas) foram misturadas. Os filmes foram obtidos pelo processo de dip-coating, com velocidade de retirada $14 \mathrm{~cm} \cdot \mathrm{min}^{-1}$. Posteriormente, os substratos revestidos foram tratados termicamente (cura) a uma temperatura próxima de $160^{\circ} \mathrm{C}$ por 3 horas sob uma taxa de aquecimento de $5^{\circ} \mathrm{C} /$ minuto. A Tabela 1Erro! Fonte de referência não encontrada. apresenta a descrição das amostras utilizadas.

Tabela 1. Descrição das amostras utilizadas

\begin{tabular}{c|c}
\hline Amostra & Foscrição \\
\hline Fl & Folha de flandres revestida com filme híbrido com adição de TEOS (nível 1), \\
com ácido nítrico e pH=3
\end{tabular}

\subsection{Caracterização dos filmes híbridos siloxano-PMMA}

Os filmes obtidos foram caracterizados quanto à morfologia por MEV, em um equipamento JEOL-JSM 5800 do centro de microscopia eletrônica da UFRGS, com tensão de aceleração 20 keV.

O ângulo de contato foi realizado pelo método da gota séssil a partir de um aparato desenvolvido pelo Laboratório Pesquisa em Corrosão (LAPEC) da Universidade Federal do Rio Grande do Sul. O ângulo de contato foi determinado por meio de um programa de análise de imagens. Foi analisado três amostras para a determinação dos valores de ângulo de contato e o desvio padrão.

Para a caracterização eletroquímica foram feitas medidas de impedância eletroquímica utilizando um potenciostato (Omnimetra Mod. PG-05) acoplado a um analisador de reposta em freqüência (Solartron 1255). As medidas foram realizadas aplicando-se um sinal senoidal de $10 \mathrm{mV}$ e varredura de $100 \mathrm{kHz}$ a $10 \mathrm{mHz}$. O eletrólito utilizado foi uma solução de $\mathrm{NaCl}$ na concentração de $0,05 \mathrm{M}$. O monitoramento do potencial de circuito aberto durante a primeira hora de imersão e as curvas de polarização potenciodinâmicas foram obtidos utilizando-se para isso um potenciostado PAR 273. As curvas de polarização foram obtidas com velocidades de varredura de $1 \mathrm{mV} / \mathrm{s}$ em uma faixa de potencial de $200 \mathrm{mV}$ (abaixo do potencial de circuito aberto) até $400 \mathrm{mV}$ (acima do potencial de circuito aberto). Os ensaios eletroquímicos foram realizados em triplicata.

\section{RESULTADOS}

\subsection{Caracterização Morfológica}

Na Figura 1 é apresentada as micrografias obtidas por MEV para os filmes híbridos estudados: T1N3 (com adição de TEOS de nível 1), T2N3 (com adição de TEOS de nível 2) e T3N3 (com adição de TEOS de nível 3). 
$68^{\text {th }}$ abm international annual congress

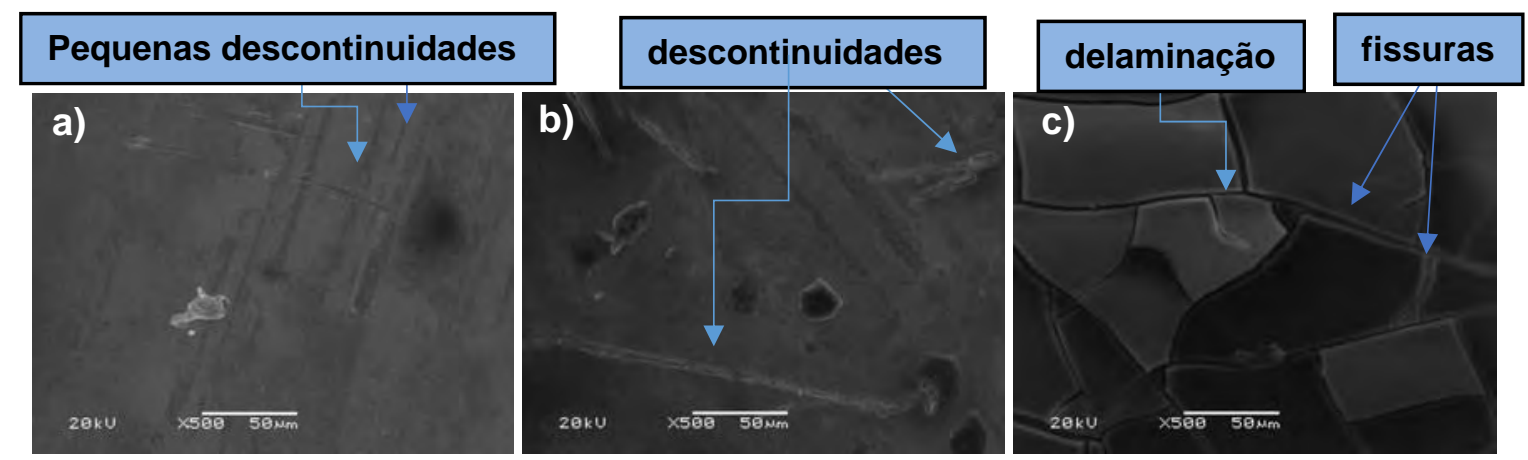

Figura 1. Micrografias obtidas por MEV para os filmes híbridos: (a) T1N3, (b) T2N3 e (c) T3N3.

A espessura de camada dos filmes por determinada por análise de imagens obtidas por MEV da secção transversal (Figura 2) e os resultados estão apresentados na Tabela 2.

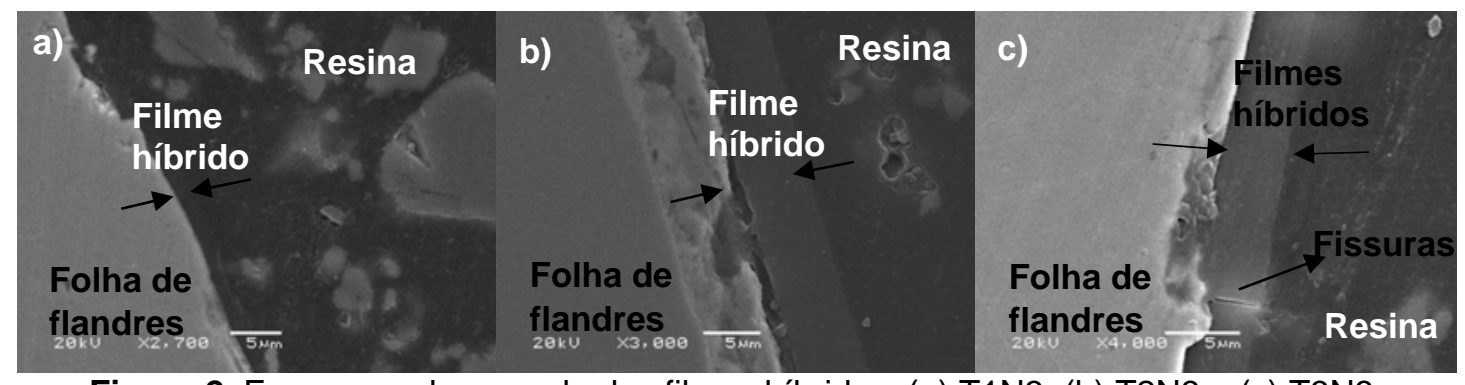

Figura 2. Espessura de camada dos filmes híbridos: (a) T1N3, (b) T2N3 e (c) T3N3.

Tabela 2. Espessura de camada dos revestimentos

\begin{tabular}{c|c|c}
\hline Amostra & Espessura $(\boldsymbol{\mu m})$ & Desvio Padrão $(\boldsymbol{\mu m})$ \\
\hline T1N3 & 1,36 & 0,39 \\
\hline T2N3 & 5,71 & 0,22 \\
\hline T3N3 & 4,07 & 0,27 \\
\hline
\end{tabular}

A Figura 3 apresenta as imagens obtidas para a determinação do ângulo de contato pelo método da gota séssil. A partir da Tabela 3 é possível observar as medidas de ângulo de contato obtidas para os sistemas estudados.

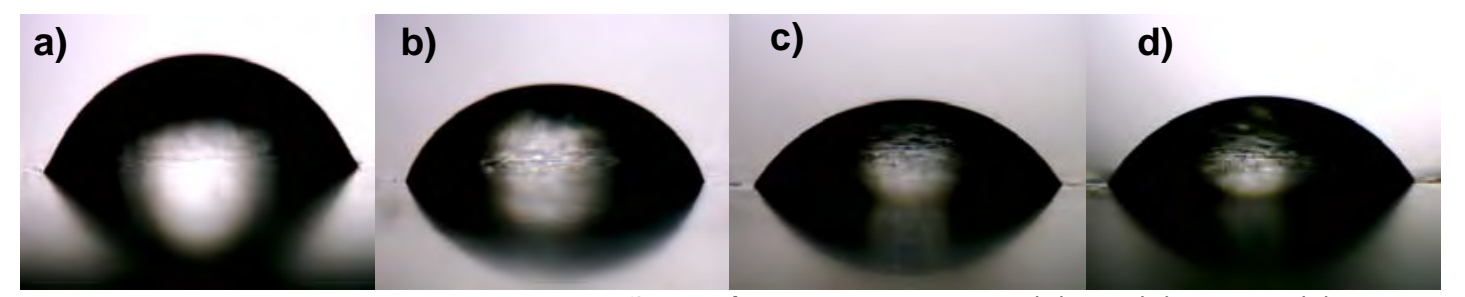

Figura 3. Imagens obtidas para determinação do ângulo de contato: (a) Fl, (b) T1N3, (c) T2N3 e (d) T3N3.

Tabela 3. Ângulo de contato médio e desvio padrão obtidos

\begin{tabular}{c|c|c}
\hline Amostra & Ângulo de contato & Desvio padrão \\
\hline $\mathrm{Fl}$ & $73^{\circ}$ & 1,9 \\
\hline $\mathrm{T} 1 \mathrm{~N} 3$ & $69^{\circ}$ & 0,5 \\
\hline $\mathrm{T} 2 \mathrm{~N} 3$ & $65^{\circ}$ & 0,6 \\
\hline T3N3 & $58^{\circ}$ & 0,4 \\
\hline
\end{tabular}




\subsection{Caracterização Eletroquímica}

Foram realizadas medidas de potencial de circuito aberto (OCP), a fim de monitorizar a variação do potencial com o tempo de imersão em solução de $\mathrm{NaCl}$ $0,05 \mathrm{M}$ (Figura 4).

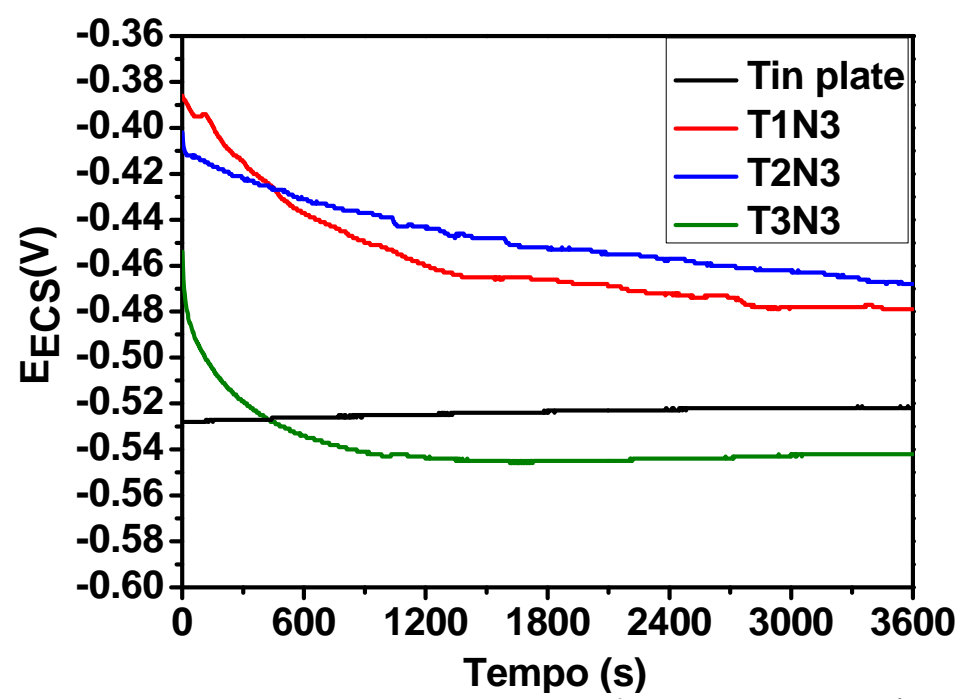

Figura 4. Curvas de potencial de circuito aberto para os filmes estudados (T1N3, T2N3 e T3N3) e para a folha de flandres sem revestimento.

A partir da extrapolação das retas de Tafel, aplicada às curvas de polarização obtidas (Figura 5) foram determinados o potencial de corrosão (Ecorr), a corrente de corrosão (Icorr) e a resistência de polarização (Rp) para os sistemas estudados (Tabela 4).

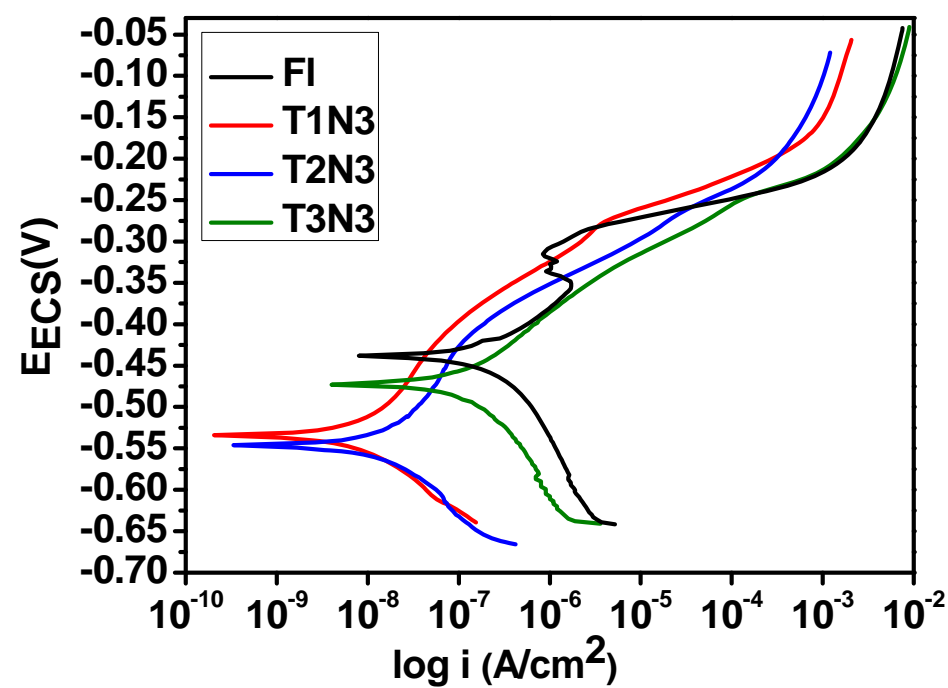

Figura 5. Curvas de polarização em solução de $\mathrm{NaCl} 0,05 \mathrm{M}$.

Tabela 4. Dados obtidos partir extrapolação das retas de Tafel

\begin{tabular}{c|c|c|c}
\hline Amostras & $\mathbf{i}_{\text {corr }}\left(\mathbf{A} / \mathbf{c m}^{\mathbf{2}}\right)$ & $\mathbf{E}_{\text {corr }}(\mathbf{m V})$ & $\mathbf{R p ~ ( \Omega )}$ \\
\hline FI & $4,71 \times 10^{-7}$ & -439 & $5,54 \times 10^{4}$ \\
\hline T1N3 & $1,87 \times 10^{-8}$ & -534 & $1,40 \times 10^{6}$ \\
\hline T2N3 & $3,25 \times 10^{-8}$ & -547 & $8,01 \times 10^{6}$ \\
\hline T3N3 & $2,62 \times 10^{-7}$ & -472 & $1,01 \times 10^{5}$ \\
\hline
\end{tabular}


Na Figura 6 estão apresentadas os diagramas de Bode obtidos por ensaio de impedância eletroquímica para os filmes estudados T1N3, T2N3 e T3N3 e para a folha de flandres sem revestimento realizados durante 96 horas em solução de $\mathrm{NaCl}$ $0,05 \mathrm{M}$.

a)
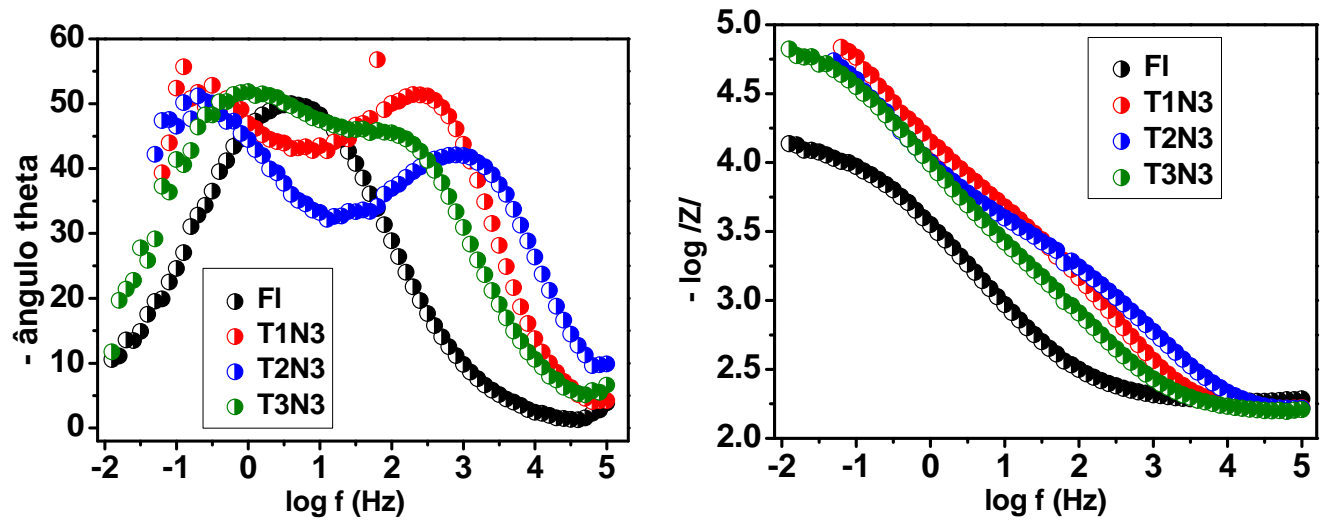

b)
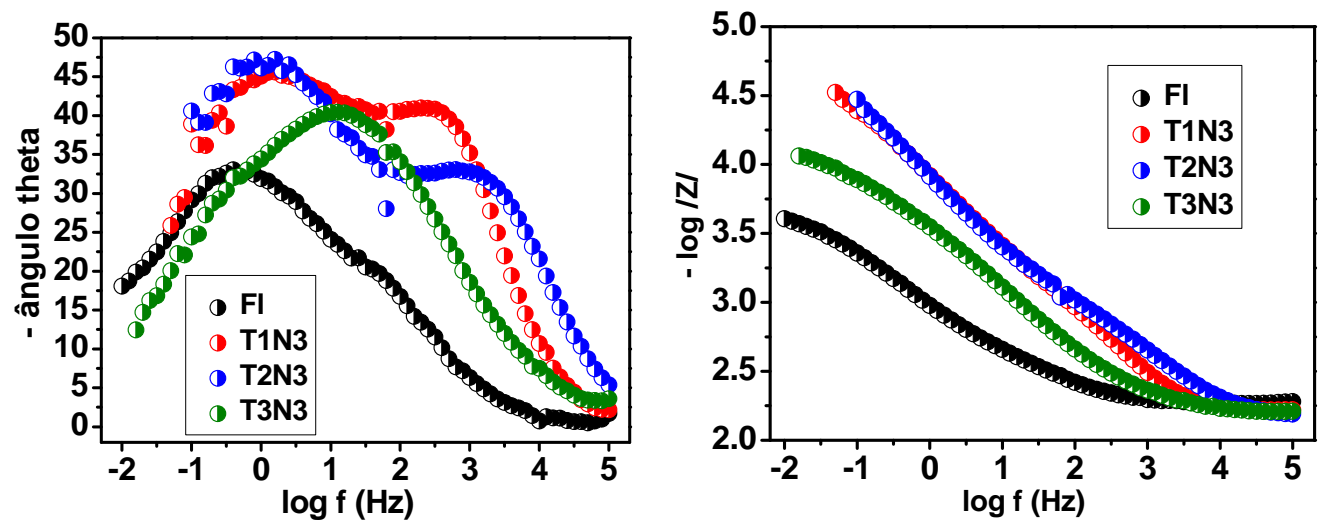

Figura 6. Diagramas de Bode obtidos para a folha de flandres sem revestimento e pós-tratado com os filmes híbridos siloxano-PMMA em solução de $\mathrm{NaCl}$ 0,05 M: (a) 24 horas de imersão e (b) 96 horas de imersão.

A Figura 7 apresenta as imagens obtidas após 96 horas de ensaio de impedância eletroquímica em solução de $\mathrm{NaCl}$ 0,05M.
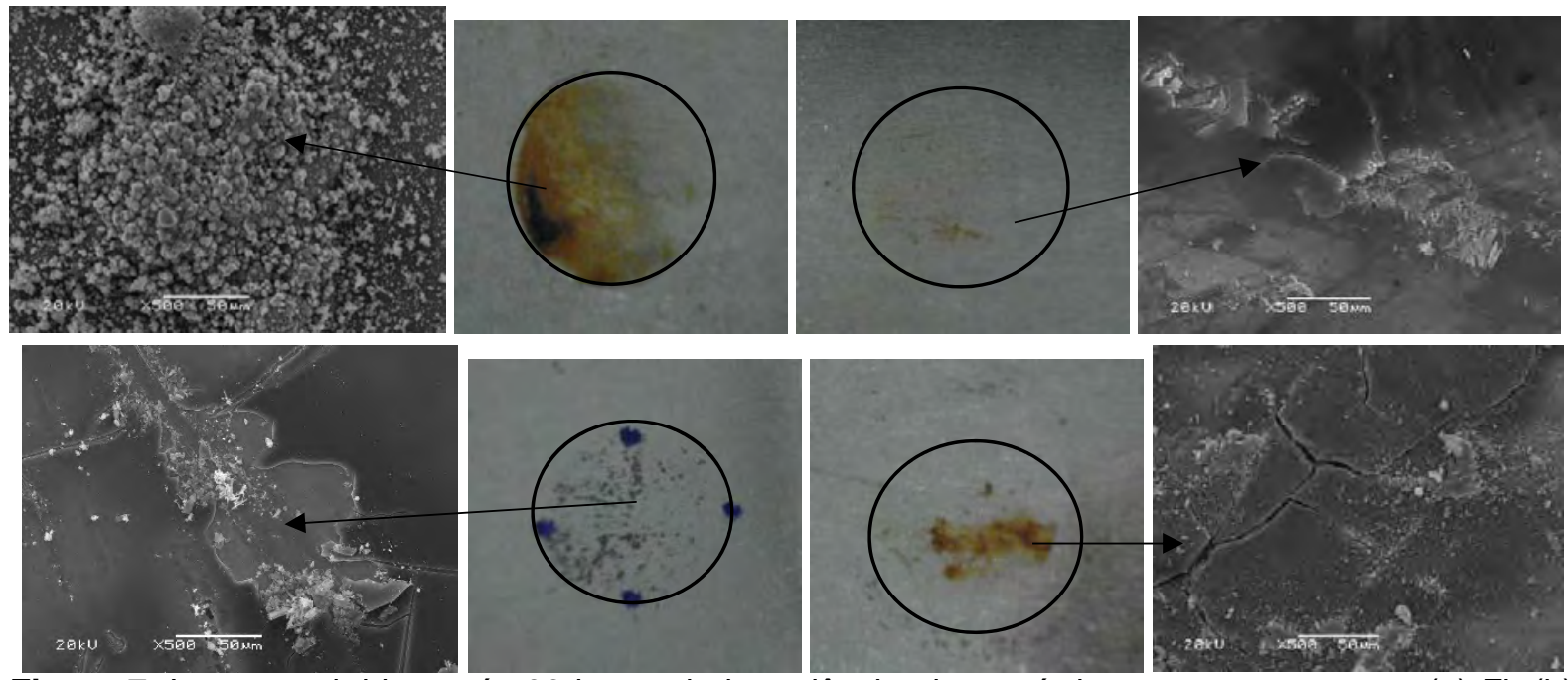

Figura 7. Imagens obtidas após 96 horas de impedância eletroquímica para as amostras: (a) Fl, (b) T1N3, (c) T2N3 e (d) T3N3. 


\section{DISCUSSÃO}

Nas micrografias obtidas por MEV (Figura 1) pode-se observar a presença de descontinuidades nos filmes híbridos T1N3 (Figura 1a) e T2N3 (Figura 1b) porém na amostra T2N3 as descontinuidade apresentaram-se de forma mais acentuada. A amostra T3N3 (Figura 1c) apresentou fissuras e delaminação do filme híbrido. Isto está associado à formação de uma estrutura porosa, ou seja, característica de um material cerâmico, que é frágil, ${ }^{(1)}$ esta formação ocorre após a hidrólise e as ligações cruzadas formadas pela adição de TEOS. Desta forma a adição TEOS contribuiu para a formação de um filme híbrido irregular.

Nos resultados de determinação de espessura de camada dos filmes híbridos (Figura 2 e Tabela 2) pode-se observar que as amostras que apresentaram maiores espessura de camada foram os filmes obtidos com maior adição de TEOS, ou seja, as amostras T2N3 e T3N3 (Figura 2b e Figura 2c). Isto é devido ao fato de que quanto maior a quantidade de TEOS no sistema maior será o teor de grupos silanóis, ou seja, maior será a quantidade de fase inorgânica (siloxano) do sistema. A densidade real do híbrido siloxano-PMMA aumenta com o teor de siloxano no sistema, pois a densidade da fase siloxano $\left(2,2 \mathrm{~g} \cdot \mathrm{cm}^{-3}\right)$ é maior que a densidade do PMMA (1,2 g. $\left.\mathrm{cm}^{-3}\right)$. Entretanto, verificou-se que para a amostra T3N3 (Figura 2c) esta apresentou fissuras devido à intensa densificação do filme promovida pela adição excessiva de TEOS.

Pelos resultados de molhabilidade (Figura 3 e Tabela 3) pode-se observar que o substrato de folhas de flandres obteve um alto valor de ângulo de contato (Figura $3 a$ e Tabela 3) isto está associado ao fato da folha de flandres apresentar na superfície uma cobertura completa ou parcial de óxidos de estanho $\left(\mathrm{SnO}_{\mathrm{x}}\right)$, a qual pode conter óxido estanoso $(\mathrm{SnO})$ ou óxido estânico $\left(\mathrm{SnO}_{2}\right)$, incluindo suas formas hidratadas aumentado o grau de hidrofobicidade. O filme híbrido T1N3 apresentou o maior valor de ângulo de contato e consequentemente a menor molhabilidade. Esse comportamento está associado a formação de mais grupos siloxanos no sistema com TEOS, formando uma rede tridimensional mais compacta impedindo a absorção da água, tornando o filme mais hidrofóbico. A amostra T3N3 apresentou maior molhabilidade (menor valor de ângulo de contato), entre as amostras estudadas. Este comportamento pode estar associado a característica hidrofílica do $\operatorname{TEOS}^{(12)} \mathrm{e}$ também devido as descontinuidades e fissuras apresentadas nesse filme.

Nos valores apresentados pelo potencial de circuito aberto (Figura 4) observou-se que os filmes estudados (T1N3 e T2N3) apresentaram valores de potenciais deslocados no sentido de potenciais menos ativos em relação à folha de flandres sem revestimento (FI). Ou seja, os revestimentos híbridos obtidos promoveram a formação de uma barreira entre o substrato e o meio.

Pelos resultados obtidos pelas curvas de polarização (Figura 5b e Tabela 4) mostraram que todos os filmes híbridos silxano-PMMA (T1N3, T2N3 e T3N3) promoveram o aumento da resistência de polarização (Rp) e a diminuição da densidade de corrente de corrosão (icorr) comparativamente ao a folha de flandres não revestida, evidenciando a ação protetiva desses filmes. Analisando somente os filmes híbridos, o filme siloxano-PMMA obtido com a maior concentração de TEOS (T3N3) apresentou maior espessura de camada que a amostra T1N3 (Tabela 2 e Figura 2c), entretanto, devido à intensa densificação do filme promovida pela adição de TEOS, houve a formação de fissuras, comprometendo assim a resistência à corrosão. 
Pelos diagramas de Bode (Figura 6), é possível observar um fenômeno em alta freqüência em todo o tempo de imersão analisado (96 horas) associado ao efeito barreira do filme híbrido apenas para as amostras T1N3 e T2N3. Isto mostra a ação protetora desses revestimentos na resistência contra à corrosão, como pode ser observado nas imagens após ensaio de impedância eletroquímica (Figura 7b e Figura 7c). Isto pode estar associado ao fato da amostra apresentar um filme mais homogéneo e sem fissuras, neste caso, a reação de condensação foi completa, devido a quantidade de TEOS ser suficiente para a formação do filme o que gerou menos grupos hidrofílicos. A amostra T3N3 (Figura 6b) apresentou menor módulo de impedância após 96 horas de imersão em relação as amostras T1N3 e T2N3, isto está de acordo com os resultados encontrados nas curvas de OCP e polarização (Figura 4 e Figura 5). O fato do filme T3N3 ter apresentado o pior desempenho eletroquímico está associado ao fato dessa amostra não apresentar uma estrutura regular, pois apesar deste filme ter apresentado uma espessura da camada maior (Tabela 2 e Figura 2c) este filme apresentou fissuras e delaminação do revestimento. Isto está associado à formação de uma estrutura porosa, ou seja, característica de um material cerâmico, que é frágil esta formação ocorre após a hidrólise e as ligações cruzadas formadas pela adição de TEOS em excesso.

Na Figura 7 observou-se que no final do experimento de impedância, a folha de flandres (Figura 7a) e o filme híbrido com a maior concentração de TEOS, a amostra T3N3 (Figura 7d) apresentaram produtos de corrosão de coloração avermelhada observada na superfície do eletrodo, indicando a formação de óxidos de ferro. (Figura 7d). O filme híbrido T2N3 apresentou os produtos de corrosão de forma mais escura indicando a degradação dos óxidos de estanho (Figura 7c) e o filme híbrido T1N3 (Figura 7b) foi o que apresentou menos produto de corrosão o que já era esperado devido bom desempenho desse filmes nos ensaios de impedância eletroquímica (Figura 6).

\section{CONCLUSÕES}

Os resultados mostraram que as amostras T1N3 e T2N3 apresentaram o melhor desempenho nos testes eletroquímicos. Para esses filmes híbridos não foram observadas a presença de fissuras. O filme de siloxano-PMMA híbrido obtido com maior concentração de TEOS (T3N3) apresentou fissuras devido à intensa densificação do filme promovida pela adição excessiva de TEOS, comprometendo desse modo a resistência à corrosão.

\section{Agradecimentos}

O presente trabalho foi realizado com o apoio da CAPES e do CNPq que são entidades do Governo Brasileiro voltadas para a formação de recursos humanos.

\section{REFERENCES}

1 Companhia Siderúrgica Nacional - CSN. Aplicações, 2005. Disponível em: http://www.csn.com.br. Acesso em 25 de julho de 2011.

2 GATTI J. Aderência de vernizes em folhas de flandres. Boletim de tecnologia e desenvolvimento de embalagens, ISSN 0104-3781, v. 20, 2008.

3 CABRAL A.M.; TRABELSI W., SERRA R., MONTEMOR M.F., ZHELUDKEVICH M.L., FERREIRA M.G.S. Corrosion Science 48 (2006).

$4 \mathrm{HU}$ H.; et al. Journal of Alloys and Compounds 472 (2009). 
5 SCHOTTNER G., Chemistry Materials 13 (2001).

6 SARMENTO V.H.V., DAHMOUCHE K., PULCINELLI S.H., SANTILLI C.V., CRAIEVICHI A.F. Journal of Applied Crystallography 36 (2003).

7 LANGROUDI A.E., GHARAZI S., Applied Surface Science 255 (2009).

8 KOZHUKHAROV S., KOZHUKHAROV V., SCHEM M., ASLAN M., WITTMAR M., WITTMAR A., VEITH M. Progress in Organic Coatings 73 (2012).

9 FEDEL M., DRUART M. E., OLIVER M., POELMAN M., DEFLORIAN F., ROSSI S. Progress in Organic Coatings 69 (2010).

10 DELATTRE L., DUPUY C., BABONNEAU F. Journal of Sol-gel Science and Thecnology 2 (1994).

11 ZHANG X., WU Y., HE S., YANG D., Surface Coating Technology 201 (2007).

12 CAIRÚ A., MITTAL K. L. UV-Resistant and Superhydrophobic Self-Cleaning Surfaces using Sol-gel Process. Ed. Netherlands / Brill; 2009. 